\title{
A EXPERIÊNCIA DE UM GRUPO DE PESQUISA NA FORMAÇÃO DE ESTUDANTES UNIVERSITÁRIOS
}

\author{
Mariliza Simonete Portela ${ }^{1}$ \\ Liceia Alves Pires ${ }^{2}$
}

RESUMO: Este artigo busca apresentar as contribuições para a formação inicial de professores propiciadas pelo Grupo de Pesquisa em História da Educação Matemática (GPHEM), constituído por professores e alunos da Educação Básica e Superior, em 2018. O grupo tem suas pesquisas na área da Educação Matemática, com uma concepção teórica baseada na História Cultural, na Cultura Escolar e na História das Disciplinas Escolares. Seu objetivo é dar oportunidade para licenciandos, dos Cursos de Matemática e Pedagogia da Universidade Estadual do Paraná (UNESPAR) do campus de Paranaguá, construírem saberes utilizando o GPHEM para discussão e construção de pesquisas em história da educação matemática. Com os resultados até então observados, tanto nas produções quanto no rendimento em disciplinas pedagógicas, espera-se que eles percebam o ensino da matemática não apenas em questões de domínio de conteúdo, mas como profissionais cuja prática esteja assentada no conhecimento social, político e cultural da história da disciplina.

Palavras-chave: História da Matemática. Licenciatura. Matemática. Pedagogia.

\section{THE EXPERIENCE OF A RESEARCH GROUP IN THE TRAINING OF UNIVERSITY STUDENTS}

ABSTRACT: This article aims to present the contributions to the initial formation of teachers provided by the Research Group on History of Mathematical Education (GPHEM), that is constituted by teachers and students from Basic and Higher Education, in 2018. Researches of this group are focused on Mathematical Education with its theoretical conception based on Cultural History, School Culture and History of School Disciplines. Its objective is to afford the opportunity to the undergraduate students of the Mathematics and Pedagogy Courses of Universidade Estadual do Paraná (UNESPAR), Paranaguá campus, a room for discussion and dissemination of History of Mathematical Education Researches. Basing on results, observed from students' productions and their better use of pedagogical disciplines, it is expected that they understand the teaching of mathematics not only in content domain issues, but as a professional whose practice is seated in social knowledge, political and cultural history of the discipline.

1 Doutora em Educação. Docente da Universidade Estadual do Paraná (UNESPAR). Paranaguá-PR/.Brasil. E-mail: mariliza.portela@gmail.com

2 Mestre em Métodos Numéricos em Engenharia. Doutoranda em Educação na Pontifícia Universidade Católica do Paraná (PUC-PR).Curitiba-PR/Brasil. Docente da Universidade Estadual do Paraná (UNESPAR). ParanaguáPR/.Brasil. E-mail: liceia.pires@unespar.edu.br 
Keywords: History of Mathematics. Degree. Mathematics. Pedagogy.

\section{LA EXPERIENCIA DE UN GRUPO DE INVESTIGACIÓN EN LA FORMACIÓN DE ESTUDIANTES UNIVERSITARIOS}

RESUMEN: Este artículo busca presentar las contribuciones en la formación inicial de los maestros propiciadas por el Grupo de Investigación en Historia de la Educación Matemática (GPHEM), constituido por profesores y alumnos de Educación Básica y Superior, en 2018. El grupo tiene sus investigaciones dirigidas al área de la Educación Matemática, con concepción teórica basada en la Historia Cultural, en la Cultura Escolar y en la Historia de las Disciplinas Escolares. Su objetivo es dar la oportunidad para licenciandos de los Cursos de Matemática y Pedagogía de la Universidad Estatal de Paraná (UNESPAR) del campus de Paranaguá, para construir saberes utilizando para ese fin un espacio de discusión y divulgación de investigaciones en historia de la educación matemática. En los resultados hasta entonces observados, en las producciones de los estudiantes y mejor aprovechamiento en las disciplinas pedagógicas, se espera que éstos perciban la enseñanza de las matemáticas no sólo en cuestiones de dominio de contenido, sino en cuanto profesionales cuya práctica esté asentada en el conocimiento social, político y cultura de la historia de la disciplina

Palabras clave: Historia de las Matemáticas. Licenciatura. Matemáticas. Pedagogía.

Ao pensar sobre a história da educação, da educação matemática e também sobre a história da disciplina de matemática entende-se que há um caminho longo a ser percorrido no que diz respeito aos entendimentos de suas constituições. O estudo e a investigação nesses campos do saber podem tornar o conhecimento profícuo quando não se restringe a disciplinas específicas em cursos de Licenciatura e/ou se limitam à responsabilidade de poucos professores pesquisadores. Na Universidade Estadual do Paraná (UNESPAR) - Paranaguá, Campus em que atuamos como professores formadores, a discussão sobre os instrumentos e métodos que contribuem para a formação dos estudantes tem sido constante nas aulas de metodologia, práticas de ensino e nas reuniões pedagógicas.

A exigência de uma sólida formação profissional nos tem feito pensar nos instrumentos que estão sendo utilizados para este fim ao mesmo tempo em que aponta para a necessidade de formar sujeitos engajados na pesquisa da sua área de formação, neste caso professores 
que ensinam matemática ${ }^{3}$. Os espaços privilegiados para esse tipo de discussão, saberes inerentes à formação e à própria matemática enquanto disciplina construída na e para a escola, são os grupos de pesquisa. Eles podem responder indagações sobre o próprio campo de trabalho e evidenciar ações coletivas na formação do professor/pesquisador.

Para Valente (2014), a formação dos professores parece viver um tempo de transição, influenciada pela quantidade de pesquisas que abrigam a Educação Matemática e esses novos profissionais que irão ensinar matemática trazem uma nova mentalidade e novas alternativas de trabalho, um movimento que ao ser sistematizado se incorpora ao corpo de rubricas curriculares. Ideia na qual apostamos ao incentivar as discussões e ações coletivas em grupos de pesquisa.A abordagem da atuação dos estudantes no grupo de pesquisa se faz, não só pela importância que o conhecimento tem gerado para a bagagem dos futuros profissionais da educação, como também pela consolidação de pesquisas na área. A validade dos estudos se apresenta na propriedade com que estes levam os conhecimentos para a sala de aula alimentando os diálogos, quando estes são oportunizados.

Nesse sentido, aqui se propõe discutir o papel que o Grupo de Pesquisas em História da Educação Matemática (GPHEM) tem exercido na formação dos estudantes de Licenciatura de Matemática e Pedagogia na Universidade Estadual do Paraná (UNESPAR), no Campus de Paranaguá. Embora o grupo de pesquisa divulgue suas reuniões para todo o Centro de Educação do Campus, até então notou-se maior interesse e permanência no grupo, das licenciaturas citadas. Acredita-se que uma das razões e motivação da participação seja a escolha dos temas e sua relação com a história da educação matemática.

A história da educação, a constituição de disciplinas que compõem o corpus de conhecimentos para ensinar matemática, na formação de professores são os elementos de discussão que se sobressaem nas propostas de estudos. Para Pinto (2010, p. 238) "[...] a matemática, como as demais disciplinas escolares tem marcas históricas que o tempo não apaga" e ao conhecer o passado das práticas dos professores e constituição da disciplina podemos, segundo a autora, "pensar em mudanças presentes e projetos futuros". Assim,

3 Usamos o termo "professores que ensinam matemática" porque entendemos que tanto o licenciado em Matemática quanto o Pedagogo estejam habilitados para ensinar matemática. Esses para os anos iniciais e aqueles para os anos finais do Ensino Fundamental e para o Ensino Médio. 
entendemos que alimentar a curiosidade natural dos estudantes sobre a história da disciplina, da formação do professor, além de instigar o espírito da pesquisa tem sido a proposta na condução do GPHEM.

\section{O contexto teórico do grupo de pesquisa - GPHEM}

Neste trabalho destaca-se, como pano de fundo das pesquisas, a história da cultura do ensino e aprendizagem da matemática, abordada na visão da história cultural, que tem como objetivo principal "[...] identificar o modo como diferentes lugares e momentos uma determinada realidade social é construída, pensada, dada a ler" (CHARTIER, 1990, p. 16). Assim, deixa-se de lado a visão dos grandes feitos, da história política ou oficial, e passa-se a ter um olhar voltado às representações da cultura dos envolvidos no lugar onde eles se encontravam, com suas tensões, conflitos, inovações e mudanças que fizeram com que a disciplina de matemática ganhasse espaço no meio escolar.

Porém, se tem claro que "[...] a história cultural deve ser mais que a soma das histórias particulares, porque se ocupa especialmente das relações entre elas, das formas específicas da organização total" (WILLIANS, 2003, p. 56). Nesse contexto objetiva-se pensar em termos de estudos de cultura as relações de todos os elementos assim como, também, de todo um modo de vida em torno de uma cultura.

Ao desenvolver estudos sobre a educação matemática na perspectiva da história cultural, há reconhecimento de que são estes movidos por representações de uma determinada cultura em um determinado tempo e realidade social específica, porém não se pode negar que

As percepções do social não são de forma alguma discursos neutros: produzem estratégias e práticas (sociais, escolares, políticas) que tendem a impor uma autoridade à custa de outros, por elas menosprezados, a legitimar ou a justificar, para os próprios indivíduos, as suas escolhas e condutas (CHARTIER, 1990, p. 17).

Dessa forma, em toda investigação realizada, quando se trata da história da cultura da disciplina, entende-se que as representações podem estar permeadas por um espaço de concorrência e de competições, disputando o poder e a dominação. Com relação à cultura 
escolar, também não é diferente, ela sofre diversificadas influências, que vêm a determinar dentro da escola o que deve ser ensinado e as práticas que envolvem esse ensinar e ao realizar estudos nesse âmbito, assim "[...] não pode ser estudada sem o exame preciso das relações conflituosas ou pacíficas que ela mantém, a cada período de sua história, com o conjunto das culturas que lhe são contemporâneas" (JULIA, 2001, p. 9).

Julia (2001) e Viñao (2001) são dois autores que têm seus estudos ligados ao campo da história das disciplinas escolares e à história da educação e buscam entender as relações que ocorrem entre os conteúdos, práticas, habitus, que ocorrem no contexto escolar. Eles têm em comum, nas suas pesquisas, a busca pelo entendimento do mundo escolar, num movimento entre sujeitos e no entorno do universo escolar. Entendem a cultura escolar a partir de normas, tradições, pensamentos, comportamentos e teorias, práticas e conteúdos. Para Viñao (2001, p. 29), a cultura escolar:

[...] estaría constituida, en una primera aproximación, por un conjunto de teorías, ideas, principios, normas, pautas, rituales, inercias, hábitos y prácticas - formas de hacer y pensar, mentalidades y comportamientos - sedimentadas a lo largo del tempo en forma de tradiciones, regularidades y regalos de juego no puestas en entredicho y compartidas por sus actores en el seno de las instituciones educativas (VIÑAO, 2001, p. 29).

Assim, a cultura escolar é um ambiente do conhecimento histórico que representa a escolarização da sociedade, e estudar esse ambiente, na perspectiva da cultura escolar, deve vir a partir de tensões e resistências, provocando reações que promovem a produção dos elementos considerados como produção cultural e até mesmo de práticas culturais. Um exemplo disso é o estudo sobre a matemática escolar ou os conteúdos escolares.

Ao estudar as disciplinas escolares, relacionadas à cultura escolar e à história cultural, entende-se que estas se constituíram historicamente dentro de um movimento de aculturação dos saberes. $O$ estudo da história das disciplinas escolares vem ganhando espaço no âmbito acadêmico e constituindo-se a partir da década de 1970 como um campo de investigação. Para Viñao (2008, p. 173) esse campo ganha espaço, “[...] sobretudo na GrãBretanha por Ivor F. Goodson, entre outros, com a influência da 'nova sociologia da educação' inglesa e dos chamados 'estudos do currículo', e na França, também entre outros, por 
Dominique Julia e André Chervel".

Ao tratar da história das disciplinas escolares, destaca-se que as disciplinas podem ser entendidas por diferentes nomes, tais como disciplinas curriculares, matérias escolares, saberes escolares, conteúdos escolares, componentes curriculares, pois entende-se que todos os nomes, em determinados momentos, se remetem ao um mesmo campo de pesquisa. Mas que é uma disciplina? Para Chervel (1990) até o final do século XIX, o termo disciplina e a expressão disciplina escolar, representavam questões de vigilância, era uma forma de repreensão a condutas que poderiam não estabelecer a ordem.

$\mathrm{Na}$ forma como ela é concebida hoje, como conteúdo de ensino, ela reaparece nos primeiros decênios do século XX, derivada do latim, com o sentido de instrução recebida pelo aluno do seu mestre, porém ela está relacionada ao verbo disciplinar, no sentido de uma ginástica intelectual, que "[...] num primeiro momento, ela passa do geral ao particular, e passa a significar uma "matéria de ensino suscetível de servir ao exercício intelectual" (CHERVEL, 1990, p. 179). Esse exercício intelectual tinha como característica, disciplinar o espírito, principalmente das crianças, que deveriam ter sua inteligência disciplinada por meio de conhecimentos e não apenas que fossem inculcados saberes durante a sua escolarização.

Com o tempo, a disciplina escolar perdeu essa característica de ginástica intelectual e passouv a se tornar apenas uma forma simplificada que classificava as matérias de ensino, sem relação com a formação do espírito. Com relação aos termos, para o autor, a disciplina é tratada como sinônimo de matérias e conteúdos e se configura como "[...] a disciplina é aquilo que se ensina e ponto final" (CHERVEL, 1990, p. 117).

Ao pensar sobre o estudo da história das disciplinas escolares, este não pode ficar restrito apenas à análise de questões epistemológicas ou didáticas, deve estar interligado com as questões políticas que os saberes, que compõem uma disciplina, desempenham dentro da conjuntura educacional. Para Bittencourt (2003, p. 10), "compreender os embates decorrentes dessa relação entre o campo epistemológico e cultural, do qual emerge a disciplina, e a esfera política é um dos desafios para quem se dedica a este tema, relativamente recente, nas pesquisas educacionais". E essa forma de compreensão é que permeia os estudos do GPHEM 
Como o grupo tem suas pesquisas no âmbito da Educação Matemática, é importante lembrar, que no Brasil, ela ganha força a partir da sua institucionalização, por volta de 1980, especialmente com a criação da Sociedade Brasileira de Educação Matemática (SBEM), em 1982. Para Valente:

\begin{abstract}
Estabelecido o campo, com assento institucional na CAPES, o movimento de pesquisas da Educação Matemática cresce a olhos vistos. Para que possam ser aquilatadas as suas dimensões, recordese que, em julho de 2013, ocorre o XI ENEM - Encontro Nacional de Educação Matemática, reunindo mais de 4500 participantes. Acrescente-se, ainda, que uma das vertentes de pesquisa que mais congrega pesquisadores na Educação Matemática é a de formação de professores (VALENTE, 2014, p. 180).
\end{abstract}

Esse novo cenário que emerge e que faz pensar, não somente sobre a matemática, mas especialmente sobre a Educação Matemática, deve também, ser colocado como pauta nos estudos que direcionam a formação do professor que ensina matemática, de modo que venha a influenciar e até auxiliar a prática desse educador. Acredita-se que não se deva pensar, somente em termos de formação do professor enquanto disciplinas pedagógicas, presentes na matriz curricular dos cursos de Matemática e Pedagogia, como por exemplos as disciplinas de prática de ensino, metodologias de ensino da matemática, dentre outras, mas também, em termos de formações e informações que ocorrem por vias não formais, como por exemplo em seminários, palestras e até mesmo grupos de estudo.

Nesse sentido, as questões que tangem a Educação Matemática poderão ser abordadas a partir de diferentes ângulos, dimensões, tempos e espaços e com isto o estudante da licenciatura poderá ter um olhar diferente sobre a sua formação, não apenas se restringindo ao estudo da matemática e de metodologias de ensino. Direcionados por esse olhar, inclusive sobre a Educação Matemática que, ao longo dos últimos anos, professores em atuação na UNESPAR/Paranaguá, pensando sobre a formação do Pedagogo e do Licenciado em Matemática, buscam dar a estes a oportunidade de discutir e pensar temas relacionados ao seu campo de atuação. Esse pensar sobre a Educação Matemática e sobre o Educador Matemático começou com pequenas reuniões entre professores e mais tarde chegou a se efetivar com a criação do GPHEM. 


\section{O contexto histórico do grupo de pesquisa - GPHEM}

O Grupo de pesquisa em História da Educação Matemática (GPHEM) é formado por professores doutores, mestres e graduandos em Licenciatura em Matemática e Pedagogia. Um grupo bastante heterogêneo em sua composição, com professores e alunos da UNESPAR e também da Secretaria Estadual de Educação do Estado do Paraná (SEED/PR), porém com um mesmo interesse, o estudo da matemática. Os encontros do grupo ocorrem quinzenalmente nas dependências da UNESPAR.

Destaca-se que a referida Universidade foi criada pela Lei Estadual $n^{\circ} 13.283$, de 25 de outubro de 2001, alterada pela Lei Estadual $n^{\circ}$ 15.500, de 28 de setembro 2006, e pela Lei Estadual no 17.590, de 12 de junho de 2013 (PARANÁ, 2011, p. 8). É uma das sete Universidades Estaduais do Estado do Paraná, estando vinculada à Secretaria de Estado da Ciência, da Tecnologia e Ensino Superior, com sede no Município de Paranavaí, e é composta por sete campi, que formam uma integração entre as faculdades isoladas.

O campus de Paranaguá, que hoje faz parte da UNESPAR, iniciou suas atividades no dia 3 de fevereiro de 1960, quando teve início o funcionamento das primeiras séries dos cursos de História, Letras Neolatinas, Pedagogia, Matemática e Letras Anglo-Germânicas, anteriormente autorizadas pela Presidência da República. Com relação ao curso de Licenciatura em matemática, quando da sua criação ele passou por algumas alterações de formato e de nome. Como já citado, ele iniciou em 1960 com a denominação Matemática, como bacharelado, na sequência, por meio do Processo no 16.711/75. Foi convertido do curso de Matemática para o "Curso de Ciências - licenciatura plena, com habilitação em Matemática" (BRASIL, 1976, p. 63)

Já em 1988, foi implantado o curso de Licenciatura Plena em Matemática e posteriormente reconhecido pelo Decreto $n^{\circ} 4.494$, de 23-07-2001. Em 1997 foi autorizado pelo Parecer no 425/97, do Conselho Estadual de Educação (CEE), publicado no Diário Oficial de 28-10-97, pelo Decreto 3907 de 30/12/1997.

Com relação ao histórico do curso de Pedagogia, assim como o de Matemática, surgiu também em 1960, como Curso de Bacharelado, formando, nesse período, bacharéis e licenciados. Posteriormente, o pedagogo passou a ser um professor de diferentes disciplinas 
do então Curso Ginasial Normal. Atualmente, segundo o Projeto Político-Pedagógico (UNIVERSIDADE ESTADUAL DO PARANÁ, 2016), o curso é denominado de Curso de Pedagogia com foco na formação de professores para atuar nos anos iniciais da escolarização.

Já com relação à formação do grupo de pesquisa, que tem como base o espaço geográfico e pessoal a UNESPAR, este se originou em 2015, como grupo de estudos, composto por alunos da Pedagogia e da Licenciatura em Matemática, tendo como Coordenadora a Profa. Dra. Mariliza Simonete Portela. Desses estudos originaram-se trabalhos de Conclusão de Curso e artigos publicados em eventos de educação com abordagem histórica da disciplina Matemática.

Um dos trabalhos desse grupo foi o artigo apresentado em 2015, na Pontifícia Universidade Católica do Paraná (PUC/PR), por estudantes do Curso de Pedagogia da UNESPAR, no XII Congresso Nacional de Educação (EDUCERE), que teve como título a "Matemática nos programas oficiais para os grupos escolares no Estado do Paraná nas primeiras décadas do século $X X^{\prime \prime}$. Para a realização do trabalho foram utilizadas fontes documentais, tais como: Regulamento da Instrução Pública; Código do Ensino do Estado do Paraná; Relatório do Diretor Geral da Instrução Pública; Programa dos Grupos Escolares do Estado do Paraná; Bases Educativas para a organização da Nova Escola Normal Paranaense e Regimento Interno e Programa para Grupos Escolares.

O trabalho apontou para a importância da formação de grupos de pesquisa para a formação de graduandos e para a constituição de fontes históricas como objeto de análise expandindo o conhecimento das disciplinas escolares. Com ele, entendeu-se a importância da investigação, da organização e da constituição de arquivos de documentos disponibilizados enquanto fontes históricas com o objetivo de análise em grupos de estudos com potencial para expandir o conhecimento de graduandos e egressos sobre a história das disciplinas escolares para alimentar sua prática de ensino.

Entendendo a necessidade de expansão, em março de 2018, constituiu-se o GPHEM, formado pelos professores Dra. Mariliza Simonete Portela, Me. Liceia Alves Pires, Me. Fernando Yudi Sakaguti, professores do Colegiado de Matemática na UNESPAR Campus Paranaguá. Na sequência começaram a participar os alunos Maria Aline Ramos Batista, Viviane 
Maurício, Gabriel Mendes Braga Cardoso da Silva; Amanda Luisa Nascimento; Gianni Grassmann Landucci; Brian Fellipe Nunes; Kauana Mahara da Silva Possobom; Felipe do Rosário Amurim; Karoline Rodrigues dos Santos; Carlos Fernando de Lorenzo Filho e o Prof. Dr. Antonio Flavio Claras - SEED/PR. Foram agregando-se ao grupo, ainda que participando de modo esporádico ao longo da caminhada, outros professores e alunos.

A inserção de discentes graduandos e egressos dos cursos de Licenciatura da UNESPAR Campus Paranaguá na pesquisa em história da educação matemática é o objetivo principal. Dele decorrem: incentivar a pesquisa histórico-cultural e comparativa na disciplina de Matemática; promover discussões teórico-metodológicas que possam expandir o quadro teórico que vem sendo construído no campo da história da Educação Matemática; estimular - levantamento de fontes históricas e a escrita da história da educação matemática principalmente de Paranaguá e região litorânea; entender a constituição das disciplinas escolares, relacionadas à matemática, no ensino superior.

O grupo tem como linha de pesquisa a constituição da disciplina Matemática, suas derivações e as orientações para seu ensino no decorrer do século XX. Ele busca compreender as mudanças no ensino da matemática no espaço escolar no decorrer do século XX. O GPHEM, conta com dois projetos de pesquisa vinculados ao grupo:

1. Os saberes matemáticos escolares no ensino paranaense no decorrer do século XX. Com vigência no período de março de 2018 a fevereiro de 2020, tendo como objetivo geral compreender as mudanças no ensino da matemática escolar no decorrer do século XX.

2. A constituição da disciplina Matemática, suas derivações e as orientações para seu ensino no decorrer do século XX. Com vigência de novembro de 2017 a outubro 2019, tem como objetivo geral entender o processo de constituição das disciplinas escolares no Brasil, sob a luz da história cultural e da história da educação, dando ênfase à disciplina de Matemática Financeira, que faz parte da Matriz Curricular de alguns cursos de Licenciatura em Matemática, seja como disciplina obrigatória ou optativa. Um dos resultados, do segundo projeto de pesquisa, é um trabalho de Iniciação Científica, desenvolvida por uma aluna do Curso de Licenciatura em Matemática, que tem 
como título o Ensino e aprendizagem de matemática financeira, a trajetória dos conteúdos e metodologias: da graduação à educação básica. O trabalho buscou analisar, por meio da comparação de documentos, como a matemática financeira é trabalhada no ensino superior, nos Cursos de Licenciatura em Matemática, nas Universidades Estaduais do Paraná, com o que deve ser trabalhado na Educação Básica no referido estado. Busca pontos em comum nas duas modalidades de ensino no que se refere a conteúdos de Matemática Financeira.

No GPHEM, em 2018, já há trabalhos em andamento que buscam investigar ou dar voz ao professor que ensinou matemática, em escolas de Paranaguá e circunvizinhança. Destacam-se aqui professores que trabalharam no contexto do Movimento da Matemática Moderna, no estado do Paraná. Esse movimento surgiu no Brasil por volta dos anos 1960 e 1970 e para Pinto (2005) foi

Desencadeado em âmbito internacional, esse movimento atingiu não somente as finalidades do ensino, como também os conteúdos tradicionais da Matemática, atribuindo uma importância primordial à axiomatização, às estruturas algébricas, à lógica e aos conjuntos (p. 2).

O movimento veio a provocar, no âmbito educacional, mudanças significativas nas práticas escolares e consequentemente na prática dos professores, que na visão do Grupo, devem ser objetos de investigação, não somente com relação as suas práticas, mas também dar voz ao professor. Para Goodson (1995),

Em primeiro lugar, tem-se dado ênfase à prática docente do professor, quase se podendo dizer ao professor enquanto "prático". Necessita-se agora de escutar acima de tudo a pessoa a quem se destina o 'desenvolvimento'. Isto significa que as estratégias a estabelecer devem facilitar, maximizar e, em sentido real, surpreender a voz do professor (p. 69).

No contexto da história cultural, em relação à educação, deixa-se de investigar os relatos históricos de grandes legisladores educacionais, de documentos oficiais e passa-se a investigar a vida das pessoas que fazem parte do alicerce educacional, o professor. Professor esse que, muitas vezes, não é ouvido, não é pesquisado, enquanto sujeito da sua própria história e da história da educação. Essas pesquisas fazem parte dos temas estudados pelo GPHEM, por entender-se que é muito importante a história de vida dos professores, quando 
se trata de estudos da cultura escolar e das disciplinas escolares, pois ele é o protagonista que atua diante do currículo e da escolarização.

No grupo também são estudados os livros didáticos de matemática, enquanto documentos que revelam uma parte da história da disciplina que pode ser contada pelos escritos escolares. A importância da análise de livros decorre de que "[...] os historiadores culturais têm de praticar a crítica das fontes, perguntar por que um dado texto ou imagem veio a existir, e se, por exemplo, seu propósito era convencer o público a realizar alguma ação" (BURKE, 2005, p. 33).

O livro didático, pode exercer diferentes funções na educação, dependendo do ambiente, época, disciplina, métodos entre outros a que se destina. Para Choppin (2004), entre outras funções ele também exerce:

\begin{abstract}
Função documental: acredita-se que o livro didático pode fornecer, sem que sua leitura seja dirigida, um conjunto de documentos, textuais ou icônicos, cuja observação ou confrontação podem vir a desenvolver o espírito crítico do aluno. Essa função surgiu muito recentemente na literatura escolar e não é universal: só é encontrada — afirmação que pode ser feita com muitas reservas — em ambientes pedagógicos que privilegiam a iniciativa pessoal da criança e visam a favorecer sua autonomia; supõe, também, um nível de formação elevado dos professores (p. 553).
\end{abstract}

Por meio do estudo dos livros, pretende-se analisar a abordagem dos conteúdos, ou seja, investigaras razões pelas quais os conteúdos são abordados desta ou daquela forma em épocas diversas. Assim, o licenciando, que participa do Grupo de Estudos, ao escolher os livros didáticos que utilizará quando estiver formado e atuando na sua área, terá um olhar diferenciado sobre o material, não apenas um olhar sob o conteúdo expresso na obra, mas também todo o contexto que o livro apresenta.

\title{
Considerações finais
}

Ao retomar a proposta inicial de escrita deste artigo, apresentar as contribuições do grupo de Pesquisa em História da Educação Matemática, para a construção de saberes pertinentes à formação dos estudantes de Pedagogia e da Licenciatura em Matemática, ocorrida ao longo dos últimos anos, nos demos conta que o investimento tem deixado um 
saldo positivo. Além da assiduidade dos membros, a oportunidade de estudar a história das disciplinas escolares, na concepção histórico-cultural, trouxe ganhos diversos para o grupo de professores e alunos envolvidos. Para os alunos, ampliando a visão da sua base profissional, para os professores da instituição uma possibilidade a mais de ter como aliado na formação, o espaço do grupo de pesquisa, um instrumento capaz de provocar mudanças no processo da educação.

\section{Referências}

BITTENCOURT, C. M. F. Disciplinas escolares: história e pesquisa. In: OLIVEIRA, Marcus Aurelio Taborda de; RANZI, Serlei Maria Fischer (org.). História das disciplinas escolares no Brasil: contribuições para o debate. Bragança Paulista: EDUSF, 2003. p. 09-38. BRASIL. Documenta. Brasília, ano 14, n. 191, p.1-410, outubro de 1976. BURKE, P. O que é história cultural? Rio de Janeiro: Jorge Zahar Ed., 2005.

CHARTIER, R. A história cultural: entre práticas e representações. Lisboa: Difel, 1990.

CHERVEL, A. História das disciplinas escolares: reflexões sobre um campo de pesquisa. Teoria \& Educação, n. 2, p. 177-229, 1990.

CHOPPIN, A. História dos livros e das edições didáticas: sobre o estado da arte. Educação e Pesquisa, São Paulo, v. 30, n. 3, p. 549-566, set./dez., 2004.

GOODSON, I. Dar voz ao professor: as histórias de vida dos professores e o seu desenvolvimento profissional. In: NÓVOA, A. Vidas de professores. Porto: Porto Editora, 1995. p. 63-78.

JULIA, D. A cultura escolar como objeto histórico. Revista Brasileira de História da Educação, n. 1, p. 9-43, jan./jun., 2001.

PARANÁ, U. E. D. Plano de Desenvolvimento Institucional: Universidade Estadual do Paraná 2012-2016. Universidade Estadual do Paraná. [S.I.], 2011. Disponível em:

file://C:/Users/Windows8/Downloads/PDI Unespar final\%20(6).pdf. Acesso em: 04 out. 2017. PINTO, N. B. Marcas Históricas da Matemática Moderna no Brasil. Revista Diálogo Educacional. Curitiba, v. 5, n. 16, p. 25-38, set/dez., 2005.

PINTO, N. B. Desafios e contribuições da História Cultural para os educadores matemáticos In: ENS, R.; BEHRENS, M. (org.). Formação do Professor: profissionalidade, pesquisa e cultura escolar. Curitiba: Champagnat, 2010. p. 225-238.

UNIVERSIDADE ESTAdUAL DO PARANÁ. Campus Paranaguá. Projeto Político-Pedagógico. 2016. VALENTE, W. R. A prática de ensino de matemática e o impacto de um novo campo de pesquisa: a educação matemática. ALEXANDRIA Revista de Educação em Ciência e Tecnologia, v. 7, n. 2, p. 179-196, 2014.

VIÑAO, A. Fracasan las reformas educativas? La respuesta de un historiador. In: Sociedade Brasileira de História da Educação (org.). Educação no Brasil: história e historiografia. Campinas: Autores Associados: SBHE, 2001. p. 21-52.

VIÑAO, A. A história das disciplinas escolares, Revista Brasileira de História da Educação. Campinas, n. 18, p. 173-215, set./dez., 2008.

WILLIAMS, R. La Larga Revolución. Buenos Aires: Nueva Vision, 2003.

Recebido em: 30/06/2018

Aprovado em: 27/08/2018 